\title{
Inferring the Relationship between Anxiety and Extraversion from Tweets during COVID-19 - A Linguistic Analytics Approach
}

\author{
Dritjon Gruda \\ National University of Ireland Maynooth \\ jon.gruda@mu.ie
}

\begin{abstract}
We investigate the longitudinal relationship between extraversion and experienced state anxiety in a cohort of Twitter users in New York using a linguistic analytics approach. We find that before COVID-19 was declared a pandemic, highly extraverted individuals experienced lower state anxiety compared to more introverted individuals. This is in line with previous literature. However, there seem to be no significant differences between individuals after the pandemic announcement, which provides evidence that COVID19 is affecting individuals regardless of their extraversion trait disposition. Finally, a longitudinal examination of the present data shows that extraversion seems to matter more greatly in the early days of the crisis and towards the end of our examined time range. Throughout the crisis, state anxiety did not seem to vary much between individuals with different extraversion dispositions.
\end{abstract}

\section{Introduction}

The year 2020 undoubtedly will be remembered as the year of the biggest health crisis in recent history the year COVID-19 spread across the globe. On March $11^{\text {th, }} 2020$ the World Health Organization officially declared COVID-19 a worldwide pandemic. Terms such as "social distancing" (i.e., maintaining a distance of at least 2 meters or 6 feet to others), to "flatten the curve" (Center for Disease Control, 2020) quickly became part of everyday vocabulary. Just one month later, over $95 \%$ of the US population was instructed to remain home and socially distance themselves from others [1]. Soon, everyone found themselves in a new and, for most, unprecedented social territory, with homes all over the world converting into offices, schools, daycares, gyms, etc. while communication to the outside world largely moved online.

To encourage individuals during these difficult times, or perhaps simply to share current feelings and emotions with others, headlines such as "we are all in this together" flooded social media and have been engraved into individuals' memories. There is solace in

\author{
Adegboyega Ojo \\ National University of Ireland Maynooth \\ adegboyega.ojo@mu.ie
}

knowing that others are in a similar situation and are sharing similar emotions of frustration, anxiety, and lack of social connection with others. Yet, these emotions might not have been experienced equally across the population. For example, some authors speculated that "extraverts might be more negatively affected by restrictions on their social life compared to introverts" [2]. While other previous literature has addressed personality differences, in particular introversion, concerning the propensity to seek out solitude and the link to well-being [3]. Hence, the question arises whether some individuals, in particular those who score low on extraversion, might be less likely to experience negative emotions, such as anxiety, throughout the COVID-19 crisis? In other words, could low levels of extraversion protect such individuals against experiencing increased levels of anxiety during this crisis?

Several previous works so far have provided evidence that extraversion is positively related to positive affect, namely a subjectively pleasant feeling [e.g., 4]. In addition, preference for aloneness, behavior which is more closely related to introverted individuals is associated with higher anxiety, depression, and emotion dysregulation [5]. Although these findings have held up in various previous works, the current COVID-19 crisis is unique in that it is a "socially distant" health crisis, which has resulted in a decrease of face-to-face interactions with others, which would imply a decrease in behavior more typically associated with extraverted individuals [2]. Hence, this current crisis provides a unique setting, in which the advantages of high introversion, having been previously associated with negative health outcomes, might serve as a protective mechanism with regard to specific health outcomes such as state anxiety. We argue that the current COVID-19 pandemic is an exogenous shock, which creates a unique and different context in which to study the possible beneficial side effects of high extraversion as well as low extraversion (or introversion) on individuals' state anxiety.

Given the recency of this health crisis, the literature on this topic (March 11 th, 2020 -present), understandably, is still scarce. For example, we found 
only one (pre-print) paper [2], in which the authors report no difference between extraverted and introverted individuals and their subjective sense of social connection, once authors controlled for "levels of social connection prior to the pandemic" [2]. The results of the study provide the first insight into the relationship between personality traits and behavior throughout this unique crisis. However, so far, there has been no literature examining the link between personality traits and experienced anxiety levels on an individual level throughout the pandemic. This paper makes a first step into this direction.

This paper makes several contributions. First, we examine the role of extraversion in predicting state anxiety throughout the COVID-19 crisis. Secondly, we apply two machine learning algorithms to determine Big Five personality scores of a sample of individuals and detect (state) anxiety over time. To do so we use microblog data on the Twitter platform, which provides a vast amount of data on millions of platform users at any given point in time. This approach allows us to determine not only anxiety changes over time per user, as outlined in Gruda and Hasan [6] and Gruda and Hasan [7], but also the frequency of experienced anxiety levels (i.e., trait anxiety). Third, we control for all Big Five personality scores, as well as trait anxiety, which allows us to more accurately make claims about the relationship between extraversion and state anxiety during the current health crisis. Finally, we showcase and relate results to previous literature.

\section{Background}

\subsection{Extraversion: The Social Personality Trait}

The Big Five (also knows as Five-Factor) Model [8] describes five personality traits, which influence individuals' psychological experiences and behavior daily [9]. The traits include openness, conscientiousness, extraversion, agreeableness, and neuroticism. Previous literature has shown that the relationship between personality traits and well-being is strong [10-12]. In particular, highly extraverted individuals consistently report higher positive (trait) affect and well-being [13].

As a trait, extraversion is composed of several facets, including "sociability, gregariousness, assertiveness, engagement in activity, sensation seeking, and susceptibility to positive affect" [12]. Hence, individuals who score high on this particular trait tend to seek social interactions and activities, act more assertively around others, and report higher levels of activated positive affect than less extraverted (or introverted) individuals [13, 14]. Extraverted individuals seek out and respond more vigorously to reward cues in their social environment [15]. In turn, highly extraverted individuals "are more disposed to encounter objectively pleasant events and display more positive thoughts [12]. Likely due to this social inclination, trait extraversion is strongly and positively associated with wellbeing [11]. Hence, on the one hand, extraverted individuals' larger social network and strong social ties likely could buffer extraverted individuals during crises or challenging environments [2].

On the other hand, the recent health crisis has required individuals to cope with increased uncertainty and anxiety about the future, and a significant drop of social interactions with others, due to imposed government restrictions and stringent social distancing measures. Previous literature has shown that prolonged deprivation of social contacts significantly reduces feelings of connection [16] and is associated with poor sleep, cognitive functioning [17], and mental health [e.g., 18, 19]. Social isolation in general affects all individuals, regardless of individual differences. However, those individuals who habitually seek out social interactions, i.e., highly extraverted individuals, are likely to be more impacted by an environment that discourages social interactions, compared to their more introverted counterparts. In general, introverts tend to have fewer social connections (and therefore interactions) than extraverted individuals [20]. Hence, concerning the current social isolation crisis, introverts potentially might be disposed to better cope with their changing environment and imposed social distancing requirements. This could be the case especially until alternative ways and sources of social connection are established and individuals slowly adapt to their new social "virtual" environment [2]. To understand better the relationship between extraversion and associated coping behavior during the current COVID-19 crisis, it is helpful to review the literature on introversion.

\subsection{Extraversion and Anxiety}

The experience of anxiety is defined by feelings of tension, worry, and apprehension [21]. State anxiety describes the experience of the above feelings temporally and is oftentimes dictated by a current or impeding event [22], e.g. an upcoming presentation in front of the entire team is likely to trigger feelings of anxiety ahead of time. However, if these feelings are experienced frequently over time, this is often referred to as trait anxiety. Trait anxiety is therefore considered a trait, or disposition towards recognizing and interpreting stimuli as threatening.

Previous literature has found that highly extraverted individuals expect positive future events more often [23] and also evaluate hypothetical events more positively 
[24]. Although these findings hint at a negative relationship between extraversion and anxiety, this relationship has been contested in subsequent studies [e.g., 25]. Therefore, additional research is required to better understand the link between extraversion and anxiety. The presented paper takes the first step in this direction. Specifically, we examine the link between extraversion and anxiety over time (i.e., state anxiety) during the COVID-19 pandemic.

\section{Method}

\section{1. Linguistic Analytics}

Linguistic-based text analytics (linguistic analytics) entails exploiting the knowledge about a language such as its syntax, semantics, and lexicons, to extract valuable insights from text. It includes using specific linguistic elements found in the text as part of the features to be used in the text mining process. For example, Ojo and Rizun [26] used linguistic markers found in patients' negative feedbacks to determine the frequency and intensity of the associated negative experience. Past studies have also shown how linguistic elements in the digital footprints of individuals and self-reports could be harnessed to monitor psychosocial health [27]. Similarly, Coppersmith, Dredze and Harman [28] showed how mental health signals can be gathered from publicly available Twitter data. Furthermore, Gruda and Hasan [6] have developed a predictive measurement tool for perceiving anxiety in tweets.
Here, we build on the following machine learningbased linguistic analytics algorithms to achieve our research goals:

1. The State and trait anxiety prediction algorithm, as described in Gruda and Hasan [6].

2. The IBM Watson Personality Insights algorithm for inferring the scores for the Big Five personality traits and associated facets [29]

These algorithms are described in more detail in Sections 3.2.2 and 3.2.3 respectively.

\section{2. The Analytical Process}

Our method comprises a five-stage process including. The first step involves extracting tweets and carefully curating our dataset (Section 3.2.1). The second step involves predicting the anxiety scores for each tweet in our dataset (Section 3.2.2). The third step in our process entails using the IBM Watson personality insights APIs to infer the Big 5 personality traits and their associated facets (Section 3.2.3). The fourth step involves integrating the datasets resulting from the second and third steps to create a dataset with both the anxiety scores and user Big 5 personality profiles (Section 3.2.4). The final step involves carrying out a longitudinal analysis of the association between anxiety and extroversion using the dataset resulting from step 4 .

Figure 1. Overall Analytical Process

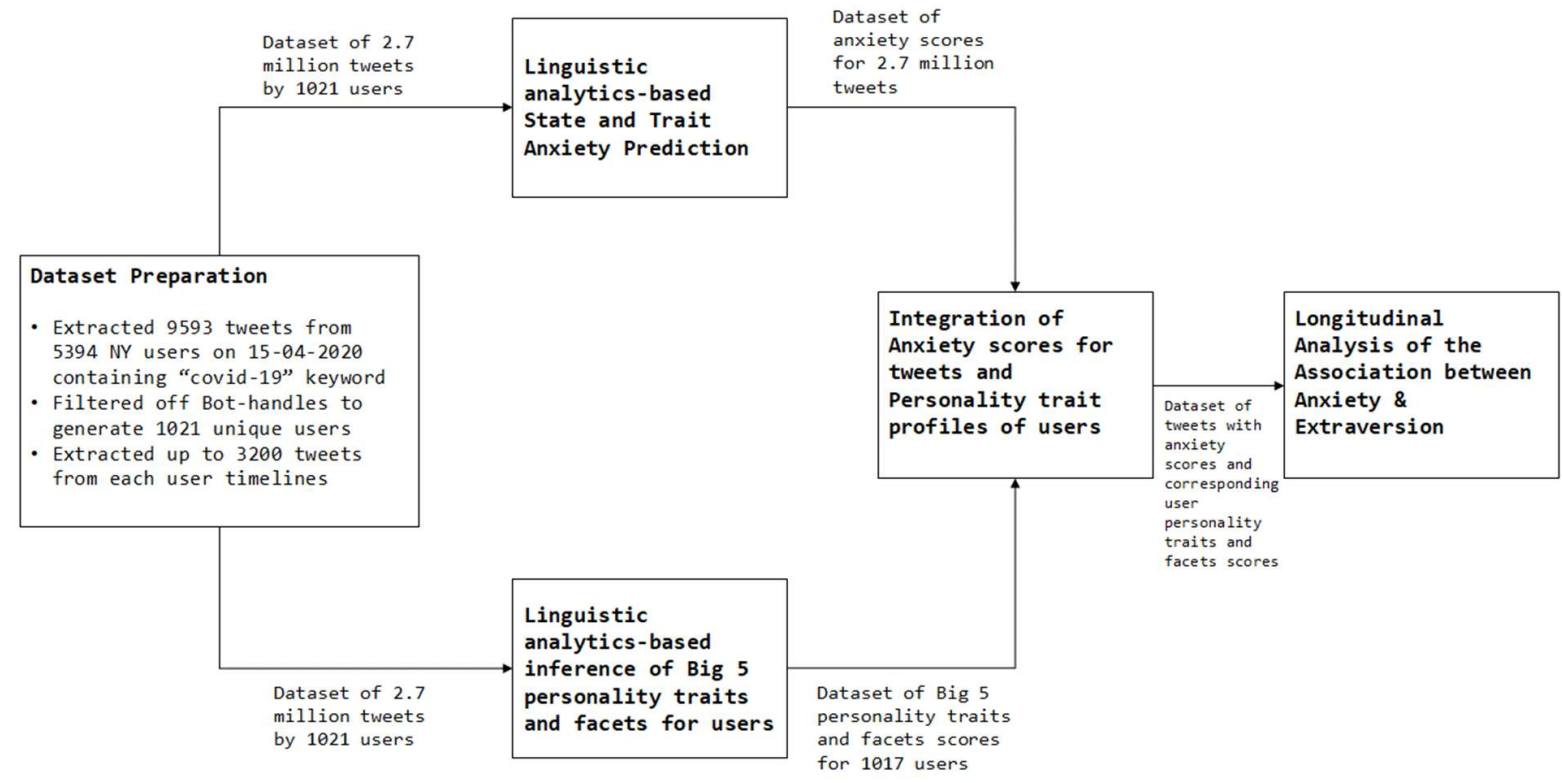


3.2.1. Dataset Preparation. This step is comprised of three tasks. The first task entailed the extraction of 9593 tweets containing the keyword "COVID-19" (i.e. tweets are all related to the coronavirus) from users whose tweets were tagged with New York as the location on $15^{\text {th }}$ April 2020. The 9593 tweets were associated with 5394 unique twitter users. The second task involved manually examining the "user ids" to filter off bots account as well as organizational accounts. The second step produced a set of 1021 unique user ids. The third task involves extracting up to 3200 tweets from the timelines of each of the 1021 users. This produced a dataset of 2.7 million tweets associated with the 1021 user ids.

3.2.2. Predicting State and Trait Anxiety Scores. We briefly describe here the state and trait anxiety prediction algorithm of Gruda and Hassan [6, 7]. The algorithm is developed using a dataset of manually rated tweets to train a machine learning model to score the perceived anxiety levels in tweets. The training set comprised of 600 tweets randomly selected from an original set of 10,510 tweets contributed by 10,386 users. At the data preparation stage, 604 participants from the US provided the perceived anxiety ratings for the tweets. Each rater labeled five (5) tweets, thus producing a total of 3020 observations. Following this, features were extracted from the texts of the tweets. Two types of features were employed in this algorithm. The first type of feature employed for the algorithm was the semantic embedding vector, which maps each word in the tweet to a distributional vector of 300 dimensions. As stated by [6], this enabled the machine learning model to better understand the similarity between words. Typically similar words have vectors closer than those of unrelated words. Thus, every tweet became a vector of 300 dimensions with each component having continuous negative or positive values [6]. The second type of feature comprised the term (including emojis) and corresponding term frequency. The machinelearning algorithm was implemented as an ensemble of two regression models corresponding to the sets of features, he best fit provided by a Bayesian Ridge Regression [7]. For the prediction of anxiety scores of non-labeled tweets, the mean of the two predicted scores from the two models constituted the final score.

3.2.3 Inferring Big 5 Personality Traits. The IBM personality insights service extracts personality insights based on how a person writes. Personality Insights API analyzes transactional and social media data to identify psychological traits and behavioral traits of an individual using linguistic analysis. Here, we have collected the twitter data of 1021 users with the respective timestamps for three months to analyze their personality traits. The API allows three types of inputs: tweets, body of text, or an individual's Twitter profile. The only condition for input text is the number of words. The API works as long as the input text is more than 100 words and the maximum limit is $20 \mathrm{MB}$ that can be analyzed by a body request. This project involves an average of 3000 tweets per user stored in respective CSV files which are extracted and inputted as a body of text in the API. The respective personality traits considered for this paper are the main Big Five personality traits [30] and their corresponding individual facets (six facets per dimension). For this paper, we derived information regarding the corresponding individual facets for each of the Big Five personality traits. In total, data for 1017 users were processed.

Figure 2. A snippet of the Big 5 Profile of a user

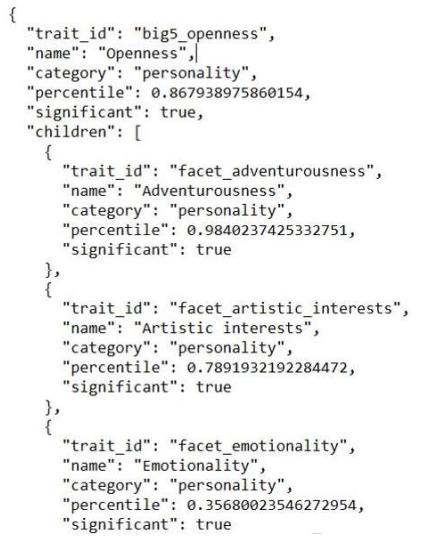

3.2.4. Integrating anxiety scores and personality trait datasets - in the fourth stage we integrated users' tweet anxiety information and their personality profiles and facets scores to enable the possibility of detailed longitudinal analysis of the relationship between anxiety levels and extraversion during the COVID-19 period.

\section{3. Measurements}

3.3.1. State Anxiety. Both state and trait anxiety scores are based on the short version of the traditional full scale (State-Trait Anxiety Inventory [STAI; [31]]. The developed algorithm in this regard is further based on multiple ratings of several tweets by the same set of human rater using the abbreviated format of the STAI composed of 6 items on a four-point scale, with $1=$ "Not at all" and $4=$ "Very much". For example, the tweet "At work feeling terrible $\odot$ )" is scored 3.4 out of 4 on averages by 6 raters, representing high state anxiety, while the tweet "Was feeling myself at work today" is 
scored 1.5 on average by 5 raters, indicating low state anxiety.

3.3.2. Trait Anxiety. Trait anxiety measures the frequency of anxiety-related experiences. Hence, we combined state anxiety scores over time to form a trait anxiety score considering all tweets per user up to and not including $1^{\text {st }}$ October 2019 . This specific point in time was chosen due to its relevance in our subsequent analyses (see Results section).

3.3.3. Big Five personality traits: Previous literature has consistently found a positive relationship between neuroticism and several health-related outcomes such as anxiety and depression [11]. Hence, in our model, we control for neuroticism as a potential contributor to state anxiety as well as all remaining Big Five personality traits using the IBM Watson Personality Insights algorithm. . Several of these facets were used and combined into higher-order Big Five personality factors (Table 1), based on Cronbach alphas (requirement: $\alpha=>$ .70). Based on previous research [9], we chose to base our analyses on individual facets rather than broad traits, since "facets provide moderate levels of incremental prediction over and above domains". Percentile scores were converted to normalized z-scores before analysis.

Table 1. Outline of included (and excluded) Big Five personality facets and dimensions

\begin{tabular}{l|l}
\hline OPEN & $\begin{array}{l}\text { Adventurousness, Artistic interests, } \\
\text { Emotionality, Imagination, Authority } \\
\text { challenging, (Intellect) }\end{array}$ \\
\hline CON & $\begin{array}{l}\text { Achievement striving, Cautiousness, } \\
\text { Dutifulness, Orderliness, Self-discipline, } \\
\text { Self-efficacy }\end{array}$ \\
\hline EXTRA & $\begin{array}{l}\text { Activity level, Assertiveness } \\
\text { Cheerfulness, Outgoing, Gregariousness, } \\
\text { (Excitement-seeking) }\end{array}$ \\
\hline AGREE & $\begin{array}{l}\text { Altruism, Cooperation, Uncompromising, } \\
\text { Sympathy, Trust, (Modesty) }\end{array}$ \\
\hline NEUROT & $\begin{array}{l}\text { Fiery. Prone to worry, Melancholy, } \\
\text { Immoderation, Self-consciousness, } \\
\text { Susceptible to stress }\end{array}$ \\
\hline Note: OPEN $=$ Openness, CON = Conscientiousness, \\
EXTRA = Extraversion, AGREE = Agreeableness, \\
NEUROT $=$ Neuroticism
\end{tabular}

\section{Results}

To estimate the association between extraversion and changes of state anxiety over time, we fit a linear regression over time. We do so in two different ways, estimating the effects of extraversion before and after corona, as well as for each recorded day of the coronavirus presence in New York. All statistical analyses presented below were conducted with Stata 16.0 [32]

\section{1. Extraversion and State Anxiety before and after the COVID-19 announcement}

Firstly, we compared the effects of extraversion on state anxiety between two different periods, namely "before corona" (BC) and "after corona" (AC) was declared a worldwide pandemic, i.e. before and after 11th March 2020. Ensuring a more balanced dataset, for comparison, the period $\mathrm{BC}$ is defined from 1st Oct-10th March 2020, which is a range of 161 days. The period AC is defined from 11th March 2020 to 23rd April, a range of 44 days. The period $\mathrm{BC}$ includes a wider range since the goal was to derive stable estimates of state anxiety given a "usual" period in any given calendar year. The results are reported in Table 2 below.

Table 2. Regression results - Association between Extraversion and State Anxiety (BC/AC)

\begin{tabular}{|c|c|c|c|c|}
\hline & M1 & M2 & M3 & M4 \\
\hline OPEN & $\begin{array}{l}.07 \\
(.80)\end{array}$ & $\begin{array}{c}.05 \\
(1.01)\end{array}$ & $\begin{array}{c}.06 \\
(1.12)\end{array}$ & $\begin{array}{c}.06 \\
(1.11)\end{array}$ \\
\hline $\mathrm{CON}$ & $\begin{array}{l}.00 \\
(.03)\end{array}$ & $\begin{array}{l}-.034 \\
(-.58)\end{array}$ & $\begin{array}{l}-.040 \\
(-.68)\end{array}$ & $\begin{array}{l}-.04 \\
(-.67)\end{array}$ \\
\hline EXTRA & $\begin{array}{l}-.50 \\
(-5.8)\end{array}$ & $\begin{array}{c}-.11 \\
(-1.98)\end{array}$ & $\begin{array}{c}-.12 \\
(-2.09)\end{array}$ & $\begin{array}{c}-.15 \\
(-2.61)\end{array}$ \\
\hline BC-AC & & & $\begin{array}{l}.06^{* * *} \\
(23.82)\end{array}$ & $\begin{array}{l}.35^{* * *} \\
(5.93)\end{array}$ \\
\hline $\begin{array}{l}\text { BC-AC X } \\
\text { EXTRA }\end{array}$ & & & & $\begin{array}{l}.11^{* *} \\
(4.95)\end{array}$ \\
\hline AGREE & $\begin{array}{l}-.06 \\
(-.55)\end{array}$ & $\begin{array}{l}-.01 \\
(-.22)\end{array}$ & $\begin{array}{c}-.01 \\
(-.18)\end{array}$ & $\begin{array}{l}-.01 \\
(-.17)\end{array}$ \\
\hline NEUROT & $\begin{array}{c}-.11 \\
(-2.21)\end{array}$ & $\begin{array}{c}-.07 \\
(-2.36)\end{array}$ & $\begin{array}{c}-.076 \\
(-2.45)\end{array}$ & $\begin{array}{l}-.08^{* *} \\
(-2.44)\end{array}$ \\
\hline TRAITANX & & $\begin{array}{c}.76 \\
(19.8)\end{array}$ & $\begin{array}{c}.754 \\
(19.7)\end{array}$ & $\begin{array}{l}.75^{* * *} \\
(19.7)\end{array}$ \\
\hline Constant & $\begin{array}{c}.65 \\
(1.55) \\
\end{array}$ & $\begin{array}{c}.06 \\
(.24)\end{array}$ & $\begin{array}{c}.04 \\
(.14) \\
\end{array}$ & $\begin{array}{c}-.04 \\
(-.17)\end{array}$ \\
\hline $\mathrm{R}^{2}$ (within) & .00 & .00 & .02 & .02 \\
\hline $\mathrm{R}^{2}$ (between) & .19 & .69 & .70 & .70 \\
\hline $\mathrm{R}^{2}$ (overall) & $.04^{* * * *}$ & $.16^{* * *}$ & $.17^{* * *}$ & $.17^{* * *}$ \\
\hline $\begin{array}{l}\quad \text { Note: } B( \\
\text { March 2020) } \\
\text { April 2020); } \\
\text { AGREE }= \\
\text { TRAITANX } \\
p<.001,{ }^{* *} p<\end{array}$ & $\begin{array}{l}=\text { Before } \\
\text { er COV } \\
\mathrm{V}=O p \\
\text { ableness } \\
\text { Anxiet } \\
=33,0\end{array}$ & $\begin{array}{l}\text { COVID- } \\
\text {-19 (11 } \\
\text { ness, E } \\
\text { NEU } \\
\text { z-statis } \\
\text { observe }\end{array}$ & $\begin{array}{l}\left(1^{\text {st }} \text { Oct. }\right. \\
\text { March } \\
R A=E x \\
T=\quad N \\
T=\quad\end{array}$ & $\begin{array}{l}19-10^{\text {th }} \\
0-23^{r d} \\
\text { version, } \\
\text { oticism; } \\
\text { eses; }{ }^{* * *} \\
\text { ividuals }^{2}\end{array}$ \\
\hline
\end{tabular}

Model 1 (Table 2) includes the independent variable, namely extraversion, as well as controls (remaining Big Five personality traits and trait anxiety). We find a negative association between 
extraversion and state anxiety $(\mathrm{M} 1 ; \mathrm{b}=-.50, \mathrm{SE}=.09$, $\mathrm{z}=-5.79, \mathrm{p}<.000)$ as well as neuroticism and state anxiety $(\mathrm{M} 1 ; \mathrm{b}=-.11, \mathrm{SE}=.05, \mathrm{z}=-2.21, \mathrm{p}=.027)$.

In Model 2 we control for trait anxiety. Compared to results in Model 1, results in Model 2 show a significant drop in the effect of extraversion (M2; $b=$ $-.11, \mathrm{SE}=.06, \mathrm{z}=-1.98, \mathrm{p}=.048)$ and neuroticism $(\mathrm{M} 2 ; \mathrm{b}=-.07, \mathrm{SE}=.03, \mathrm{z}=-2.36, \mathrm{p}=.018)$ on state anxiety. Although the relationship between neuroticism and state anxiety is negative, this result is not entirely unexpected. We discuss this particular result further in the discussion section.

In Model 3 we introduce our BC-AC (dummy) variable. Results show that state anxiety increases substantially between the two considered time periods $(\mathrm{M} 2 ; \mathrm{b}=.06, \mathrm{SE}=.00, \mathrm{z}=23.82, \mathrm{p}<.000)$. All other coefficients remain largely the same (see M3, Table 1), compared to Model 2. Finally, in Model 4 we examine the relationship between extraversion and state anxiety, comparing periods BC and AC. Results show a positive relationship between state anxiety and the interaction of extraversion and BC-AC (M4, =.11, $\mathrm{SE}=.02, \mathrm{z}=4.95, \mathrm{p}<.000)$. To understand this interaction further, we graph the result accordingly in Figure 3 (+/- $1 \mathrm{SD})$.

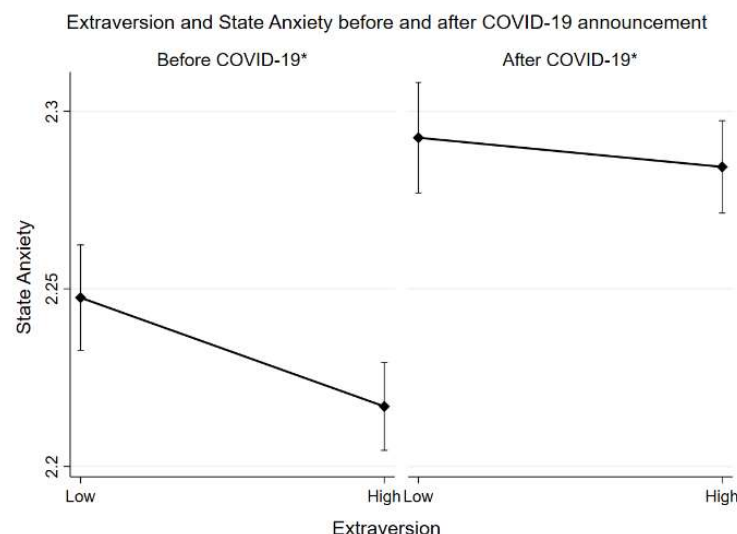

Figure 3. Association between extraversion and state anxiety (before/after COVID-19*)

Note: * = announcement; Before COVID-19 (1 ${ }^{\text {st }}$ Oct. 2019 - $10^{\text {th }}$ March 2020) - After COVID-19 (1 $11^{\text {th }}$ March 2020 $23^{\text {rd }}$ April 2020); Figure includes respective 95\% Confidence Intervals, $n=33,049$ (233 individuals)

Results again show that state anxiety is significantly lower $\mathrm{BC}$ compared to $\mathrm{AC}$, regardless of whether participants score low $(\mathrm{BC}: \mathrm{M}=2.25, \mathrm{SD}=$ $.01 ; \mathrm{AC}: \mathrm{M}=2.29, \mathrm{SD}=.01$ ) or high on extraversion $(\mathrm{BC}: \mathrm{M}=2.22, \mathrm{SD}=.01 ; \mathrm{AC}: \mathrm{M}=2.28, \mathrm{SD}=.01$ ). And although the difference of effects between participants who score low and high on extraversion on state anxiety is significant BC $(\mathrm{z}=-2.61, \mathrm{p}=.05)$, no significant difference was found with regard to the period $\mathrm{AC}(\mathrm{z}=-.68, \mathrm{p}>.10)$. We elaborate on these results in the discussion section.

In addition, a pairwise comparison of predictive margins indicated that highly extraverted participants showed a larger change of state anxiety levels between $\mathrm{BC}$-AC (delta $=.07, \mathrm{SE}=.00, \mathrm{z}=21.56, \mathrm{p}<.000)$ compared to participants who scored low on extraversion (delta $=.05, \mathrm{SE}=.00, \mathrm{z}=12.82, \mathrm{p}<$ $.000)$. Subsequent analyses using a Bonferroni correction showed that these differences were significant (delta $=.02, \mathrm{SE}=.01, \mathrm{z}=4.95, \mathrm{p}<.000$ ).

In sum, substantial differences were found in the relationship between state anxiety and extraversion before and after COVID-19. However, state anxiety changes over time. And although the above regressions consider temporary changes over time, the BC-AC specification is too binary to yield deep insights into the dynamic relationship between extraversion and state anxiety. We build a more complex model in the next section.

\subsection{Extraversion and State Anxiety over Time (Daily Analysis)}

To understand the relationship between extraversion and state anxiety, we build a model to account for changes over time between our two variables of interest, namely for each day of recorded cases of COVID-19 in New York. An overview of cases, hospitalized cases (referred to as hospitalizations), and deaths is provided in Figure 4.

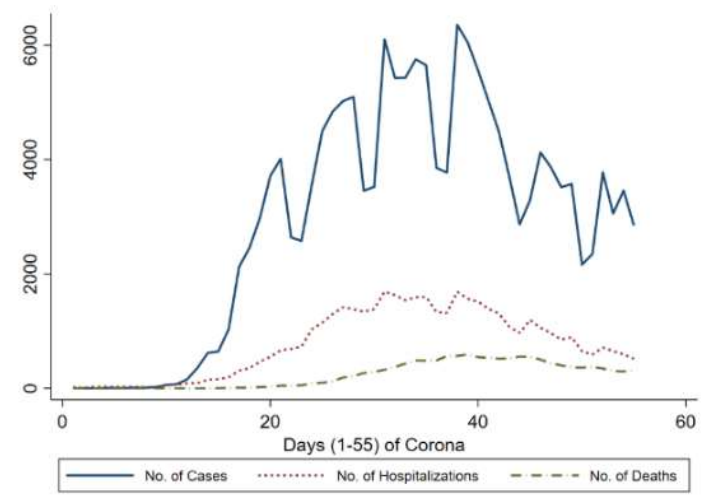

Figure 4. Overview of Cases, Hospitalizations, and Deaths due to COVID-19 in New York 
Table 3. Regression results - Association between Extraversion and State Anxiety over Time

\begin{tabular}{|c|c|}
\hline Openness & .03 \\
\hline Conscientiousness & -.06 \\
\hline Extraversion & $-.30^{*}$ \\
\hline D1 X EXTRA & (base level) \\
\hline D2 X EXTRA & $.56^{* *}$ \\
\hline D5 X EXTRA & $.42^{*}$ \\
\hline D10 X EXTRA & $.37^{*}$ \\
\hline D14 X EXTRA & $.47^{* *}$ \\
\hline D15 X EXTRA & $.34^{*}$ \\
\hline D16 X EXTRA & $.44^{* *}$ \\
\hline D17 X EXTRA & $.42^{*}$ \\
\hline Day 22 X EXTRA & $.35^{*}$ \\
\hline Day 23 X EXTRA & $.36^{*}$ \\
\hline Day 25 X EXTRA & $.36^{*}$ \\
\hline Day 29 X EXTRA & $.41^{*}$ \\
\hline Day 30 X EXTRA & $.44^{* *}$ \\
\hline Day 39 X EXTRA & $.38^{*}$ \\
\hline Day 40 X EXTRA & $.31^{*}$ \\
\hline Day 51 X EXTRA & $.38^{*}$ \\
\hline Day 54 X EXTRA & $.46^{* *}$ \\
\hline Day 55 X EXTRA & $.81^{* * *}$ \\
\hline $\begin{array}{l}\text { Agreeableness } \\
\text { Neuroticism } \\
\text { Trait Anxiety } \\
\text { Constant }\end{array}$ & $\begin{array}{l}.03 \\
-.06 \\
.64^{* * *} \\
-.17\end{array}$ \\
\hline $\mathrm{R}^{2}$ (within) & .03 \\
\hline $\mathrm{R}^{2}$ (between) & .56 \\
\hline $\mathrm{R}^{2}$ (overall) & .16 \\
\hline \multicolumn{2}{|c|}{$\begin{array}{l}\text { Note: Model includes days (1-55), only significant interaction } \\
\text { shown; } D=\text { Day, D1 }\left(29^{\text {th }} \text { February 2020), D55 }\left(23^{\text {rd }} \text { April }\right.\right. \\
\text { 2020); EXTRA = Extraversion; }{ }^{* * *} p<0.001,{ }^{* *} p<0.01,{ }^{*} \\
p<0.05 ; n=9,049,194 \text { individuals. }\end{array}$} \\
\hline \multicolumn{2}{|c|}{$\begin{array}{l}\text { Further, we examined the relationship between } \\
\text { extraversion and state anxiety, comparing daily } \\
\text { changes, beginning with the first day of COVID- } 19 \\
\text { recorded cases in New York (Table } 3 \text { ). We build one } \\
\text { model, which includes all control variables, namely all } \\
\text { remaining Big Five personality traits, trait anxiety, and } \\
\text { all recorded days after the first record of COVID-19 in } \\
\text { New York (since } 29^{\text {th }} \text { February } 2020 \text { ). Results show } \\
\text { that, overall, the relationship between state anxiety and } \\
\text { the interaction between extraversion and days of } \\
\text { COVID-19 is positive for several days (e.g., for Day } \\
2: \mathrm{b}=.56, \mathrm{SE}=.18, \mathrm{z}=3.09, \mathrm{p}=.002 \text {; for Day } 25: \mathrm{b} \\
=.36, \mathrm{SE}=.16, \mathrm{z}=2.20, \mathrm{p}=.028 \text {; and for Day } 55: \mathrm{b} \\
=.81, \mathrm{SE}=.22, \mathrm{z}=3.70, \mathrm{p}<.000 \text { ). }\end{array}$} \\
\hline
\end{tabular}

To understand this interaction further, we graph results accordingly in Figure 5.

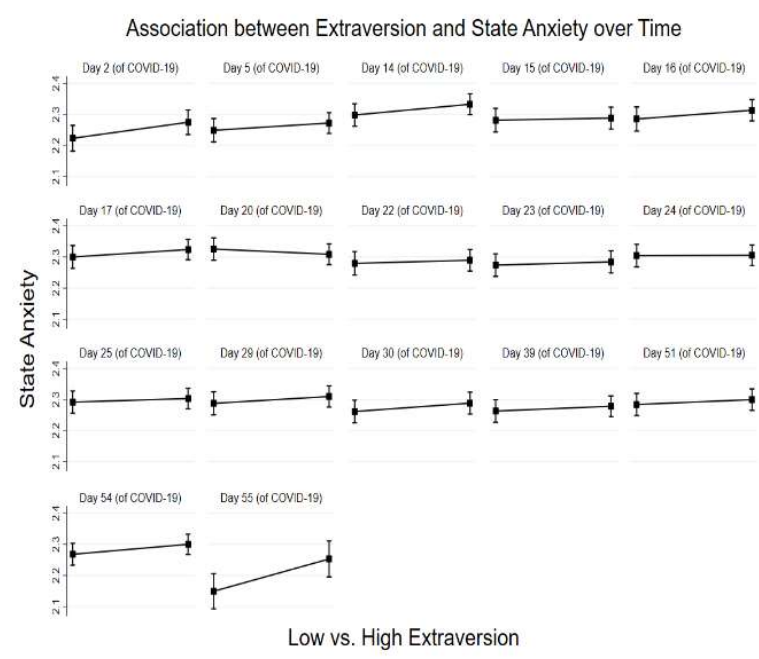

Figure 5. Association between EXTRA and State Anxiety over Time*

Note: Time $=$ first 55 days of COVID-19 in New York $\left(29^{\text {th }}\right.$ February 2020 - 23 $3^{\text {rd }}$ April 2020), figure shows only significant interactions, $n=9,049,194$ individuals.

Simple slope analyses show that extraversion seems to matter in the beginning of the crisis, with highly extraverted participants experiencing more state anxiety (e.g., for Day 2: delta $=.06, \mathrm{SE}=.03, \mathrm{z}$ $=2.27, p=.023)$ compared to their more introverted counterparts (for Day 2: delta $=-.06, \mathrm{SE}=.03, \mathrm{z}=-$ $2.02, p=.043)$. However, these differences between highly and less extraverted participants seem to become smaller or even dissipate completely a few days into the crisis, as the crisis begins affecting all individuals. For example, by Day 19, both highly and less extraverted individuals seem to experience increased levels of state anxiety (high extraversion: $b$ $=.09, \mathrm{SE}=.02, \mathrm{z}=3.72, \mathrm{p}<.000$; low extraversion: delta $=.05, \mathrm{SE}=.02, \mathrm{z}=2.19, \mathrm{p}=.028)$. Interestingly, as the crisis continues (e.g., by Day 55), less extraverted participants report lower state anxiety compared to base levels (delta $=-.13, \mathrm{SE}=.03, \mathrm{z}=$ $3.86, \mathrm{p}<.000$ ), while this is not the case for highly extraverted individuals (delta $=.04, \mathrm{SE}=.03, \mathrm{z}=1.09$, $\mathrm{p}=.27)$. Results are discussed further in the discussion section below.

\section{Discussion}

Previous research has shown a positive link between extraversion and beneficial health outcomes such as happiness and a negative association with 
anxiety [33]. While we do not doubt this to be the case, the current exogenous shock triggered by the COVID19 pandemic has produced a very unique context to study the possible beneficial side effects of high extraversion as well as low extraversion (or introversion) on individuals' state anxiety.

Firstly, we find that the COVID-19 crisis has increased the state anxiety scores of both highly extraverted and introverted participants. Hence, we find increased levels of state anxiety in our sample when comparing periods before and after COVID-19 had been declared a pandemic. This is to be expected as most individuals all over the world have had to come to terms with a new reality, marked by uncertainty and worry. In support of this finding, we found no significant difference between highly extraverted and introverted individuals in the period after COVID-19 had been declared a pandemic. However, we did find significant differences between highly extraverted and introverted individuals in the period before COVID-19 was declared a pandemic. Results examining the period before the pandemic announcement show that highly extraverted individuals do report lower state anxiety levels compared to more introverted individuals. These results are in line with previously mentioned studies $[\mathrm{e}, \mathrm{g}, 33]$, which took place years before the current context. Likewise, our results also underline the importance of context and environment when studying the impact of personality traits on anxiety and other health outcomes.

Secondly, while examining the link between extraversion and state anxiety on a day-to-day basis (Day 1 - Day 55), we find a positive relationship between extraversion and state anxiety. A closer examination of these results indicates that the relationship between extraversion and state anxiety, although stable towards mid-points of our day range, can vary considerably particularly at the beginning (e.g., Day 2) as well as after the amount of cases reaches its peak and begins to drop and stabilize (i.e., Day 55). Hence, at the beginning of the crisis (Day 2) and towards the end-range of our data set, we do find that less extraverted individuals seem to experience lower state anxiety scores compared to highly extraverted individuals. It is reasonable to suggest that, based on previous research (Steers et al., 2016), introverts are indeed less likely to be affected by COVID-19 but only so in the beginning of the crisis and towards the end of our examined time range (e.g., Day 54). It might well be that when the crisis commenced, introverts did not have the same worries as highly extraverted individuals. Highly extraverted individuals would be more likely to worry about not being as socially active as they were before restrictions on physical meetings etc. become the new reality. We would expect these worries to be reflected in higher state anxiety scores.

However, as the crisis continued highly extraverted and more introverted individuals begin to experience similar levels of state anxiety (e.g., Day 22 ), with a significant change once again to be found towards the end of our examined time range. This difference in state anxiety scores by this point of the crisis might be due to several reasons, e.g., further changes in more stringent movement restrictions (e.g., limiting public transport, etc.), which might further worry those individuals who are more eager to socialize and meet with others. A more comprehensive analysis using additional (time-sensitive) data is required to account for these changes more accurately over time.

\section{Limitations and Future Research}

Our presented study is not without limitation. Firstly, the most important limitation is our sample size of examined individuals and time range. These limitations are mostly due to the early date of data collection (24 ${ }^{\text {th }}$ April 2020). A future study is currently underway to overcome these limitations by examining a much larger sample of Twitter users and a longer timeframe of COVID-19.

Secondly, our results, and the interpretation thereof, might have been due to other factors we have not considered. For example, previous research [34] has found that introverts are less susceptible to reward cues and hence less able to detect approval by other people; highly extraverted are much more likely to respond and be susceptible to reward cues and approval of others. And this positive link between extraversion and susceptibility for approval is much more likely to be impacted (negatively) due to the ongoing crisis and introduction of behavioral changes, i.e. social distancing, not being able to meet others face-to-face, etc. However, as individuals begin to come to terms with the crisis and imposed restrictions on mobility, these behaviors might be able to transfer online [19] allowing highly extraverted individuals to form and maintain social ties to others [35]. We do find some possible support for this pattern since our results show that extraversion seems to matter most at the early beginning of the COVID-19 crisis and towards the end of our examined time range. However, again, additional data is required to account for these changes more accurately over time. 


\section{Conclusion}

With over 330 million active monthly users, Twitter provides an enormous and continuous stream of user information publicly and longitudinally. And with the current COVID-19 crisis impacting individuals around the world, social media represents a unique opportunity to study the interplay of exogenous shocks and individual differences, such as anxiety and personality, over time. This is especially advantageous as the continuous analysis of user data can help identify particularly crucial points in time during which anxiety peaks. At the same time, our analysis also provides insights into how different users, based on their personality traits, experience anxiety on a dayto-day basis while living through the greatest pandemic in recent history.

We find that both introverted and highly extraverted individuals seem to experience higher state anxiety during the respective COVID-19 period, while the change in state anxiety between $\mathrm{BC}$ and $\mathrm{AC}$ is significantly higher in highly extraverted users, compared to more introverted users. Hence, it seems that being more introverted is associated with a lower increase in anxiety levels. However, a longitudinal day-by-day analysis showed that this difference in extraversion seems to matter less and less as a predictor of experienced anxiety as the crisis went on, with much greater relevance at the beginning of the crisis.

\section{References}

[1] S. Mervosh, D. Lu, and V. Swales, "See which states and cities have told residents to stay at home," New York Times, 2020.

[2] D. Folk, K. Okabe-Miyamoto, E. Dunn, and S. Lyubomirsky, "Have Introverts or Extraverts Declined in Social Connection During the First Wave of COVID-19?" 2020.

[3] J. M. Zelenski, K. Sobocko, and D. C. Whelan, "Introversion, solitude, and subjective well-being," The handbook of solitude: Psychological perspectives on social isolation, social withdrawal, and being alone, pp. 184-201, 2014.

[4] J. M. McNiel, and W. Fleeson, "The causal effects of extraversion on positive affect and neuroticism on negative affect: Manipulating state extraversion and state neuroticism in an experimental approach," Journal of Research in Personality, vol. 40, no. 5, pp. 529-550, 2006.
[5] T.-v. Nguyen, N. Weinstein, and R. Ryan, "Unpacking the "Why" of Time Spent Alone: Who Prefers and Who Chooses it Autonomously?," 2018.

[6] D. Gruda, and S. Hasan, "Feeling anxious? Perceiving anxiety in tweets using machine learning," Computers in Human Behavior, vol. 98, pp. 245-255, 2019.

[7] D. Gruda, and S. Hasan, "You're Anxious and I know it! A Machine Learning Approach to perceiving Anxiety in Micro-Blog Data." p. 17625.

[8] R. R. McCrae, and A. R. Sutin, "A five-factor theory perspective on causal analysis," European Journal of Personality, vol. 32, no. 3, pp. 151-166, 2018.

[9] J. Borghuis, J. Denissen, K. Sijtsma, S. Branje, W. H. Meeus, and W. Bleidorn, "Borghuis et al.(2018). Positive daily experiences are associated with personality trait changes in middle-aged mothers," 2019.

[10] G. E. Gignac, and E. T. Szodorai, "Effect size guidelines for individual differences researchers," Personality and individual differences, vol. 102, pp. 74-78, 2016.

[11] J. Anglim, S. Horwood, L. D. Smillie, R. J. Marrero, and J. K. Wood, "Predicting psychological and subjective well-being from personality: A meta-analysis," Psychological Bulletin, vol. 146, no. 4, pp. 279, 2020.

[12] B. Dauvier, J.-B. Pavani, S. Le Vigouroux, J.L. Kop, and A. Congard, "The interactive effect of neuroticism and extraversion on the daily variability of affective states," Journal of Research in Personality, vol. 78, pp. 1-15, 2019.

[13] C. J. Soto, "Is happiness good for your personality? Concurrent and prospective relations of the big five with subjective wellbeing," Journal of personality, vol. 83, no. 1, pp. 45-55, 2015.

[14] L. D. Smillie, C. G. DeYoung, and P. J. Hall, "Clarifying the relation between extraversion and positive affect," Journal of Personality, vol. 83, no. 5, pp. 564-574, 2015.

[15] L. D. Smillie, A. J. Cooper, J. Wilt, and W. Revelle, "Do extraverts get more bang for the buck? Refining the affective-reactivity hypothesis of extraversion," Journal of personality and social psychology, vol. 103, no. 2, pp. 306, 2012.

[16] J. Sun, K. Harris, and S. Vazire, "Is wellbeing associated with the quantity and quality 
of social interactions?," Journal of Personality and Social Psychology, 2019.

[17] J. T. Cacioppo, L. C. Hawkley, G. J. Norman, and G. G. Berntson, "Social isolation," Annals of the New York Academy of Sciences, vol. 1231, no. 1, pp. 17, 2011.

[18] N. K. Valtorta, M. Kanaan, S. Gilbody, S. Ronzi, and B. Hanratty, "Loneliness and social isolation as risk factors for coronary heart disease and stroke: systematic review and meta-analysis of longitudinal observational studies," Heart, vol. 102, no. 13, pp. 1009-1016, 2016.

[19] E. O. Whaite, A. Shensa, J. E. Sidani, J. B. Colditz, and B. A. Primack, "Social media use, personality characteristics, and social isolation among young adults in the United States," Personality and Individual Differences, vol. 124, pp. 45-50, 2018.

[20] S. Srivastava, K. M. Angelo, and S. R. Vallereux, "Extraversion and positive affect: A day reconstruction study of personenvironment transactions," Journal of Research in Personality, vol. 42, no. 6, pp. 1613-1618, 2008.

[21] C. D. Spielberger, R. L. Gorsuch, R. Lushene, P. R. Vagg, and G. Jacobs, Statetrait anxiety inventory for adults: Mind Garden, 1983.

[22] R. B. Cattell, and I. H. Scheier, "The meaning and measurement of neuroticism and anxiety," 1961.

[23] J. M. Zelenski, and R. J. Larsen, "Predicting the future: How affect-related personality traits influence likelihood judgments of future events," Personality and Social Psychology Bulletin, vol. 28, no. 7, pp. 10001010, 2002.

[24] L. Uziel, "The extraverted and the neurotic glasses are of different colors," Personality and Individual Differences, vol. 41, no. 4, pp. 745-754, 2006.

[25] P. Jylhä, and E. Isometsä, "The relationship of neuroticism and extraversion to symptoms of anxiety and depression in the general population," Depression and anxiety, vol. 23, no. 5, pp. 281-289, 2006.

[26] A. Ojo, and N. Rizun, "Enabling Deeper Linguistic-Based Text Analytics-Construct Development for the Criticality of Negative Service Experience," IEEE Access, vol. 7, pp. 169217-169256, 2019.

[27] N. Smith, "Relations between self-reported and linguistic monitoring assessments of affective experience in an extreme environment," Wilderness \& environmental medicine, vol. 29, no. 1, pp. 61-65, 2018.

[28] G. Coppersmith, M. Dredze, and C. Harman, "Quantifying mental health signals in Twitter." pp. 51-60.

[29] A. Gliozzo, C. Ackerson, R. Bhattacharya, A Goering, A. Jumba, S. Y. Kim, L. Krishnamurthy, T. Lam, A. Littera, and I. McIntosh, Building Cognitive Applications with IBM Watson Services: Volume 1 Getting Started: IBM Redbooks, 2017.

[30] P. T. Costa, and R. R. McCrae, "Normal personality assessment in clinical practice: The NEO Personality Inventory," Psychological Assessment, vol. 4, no. 1, pp. 5, 1992.

[31] T. M. Marteau, and H. Bekker, "The development of a six-item short-form of the state scale of the Spielberger State-Trait Anxiety Inventory (STAI)," British Journal of Clinical Psychology, vol. 31, no. 3, pp. 301-306, 1992.

[32] StataCorp, "Stata Statistical Software: Release 16," StataCorp LLC, 2019.

[33] H. Cheng, and A. Furnham, "Personality, self-esteem, and demographic predictions of happiness and depression," Personality and individual differences, vol. 34, no. 6, pp.921942, 2003.

[34] M.-L. N. Steers, M. C. Quist, J. L. Bryan, D. W. Foster, C. M. Young, and C. Neighbors, "I want you to like me: Extraversion, need for approval, and time on Facebook as predictors of anxiety," Translational issues in psychological science, vol. 2, no. 3, pp. 283, 2016.

[35] G. Mark, and Y. Ganzach, "Personality and Internet usage: A large-scale representative study of young adults," Computers in Human Behavior, vol. 36, pp. 274-281, 2014. 